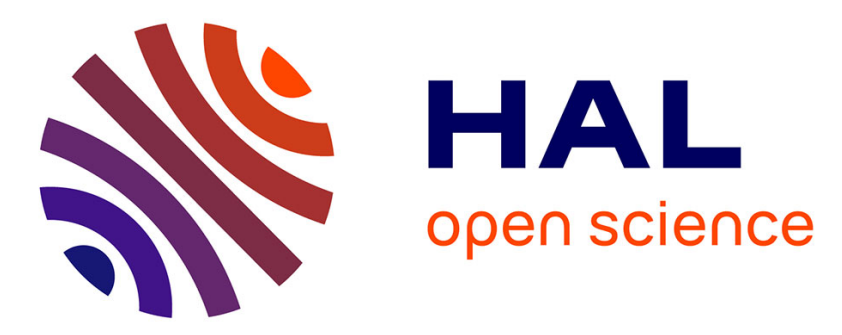

\title{
Joint integrated production-maintenance policy with production plan smoothing through production rate control
}

Sofiene Dellagi, Anis Chelbi, Wajdi Trabelsi

\section{- To cite this version:}

Sofiene Dellagi, Anis Chelbi, Wajdi Trabelsi. Joint integrated production-maintenance policy with production plan smoothing through production rate control. Journal of Manufacturing Systems, 2017, 42, pp.262-270. 10.1016/j.jmsy.2016.12.013 . hal-01493305

\section{HAL Id: hal-01493305 \\ https://hal.science/hal-01493305}

Submitted on 21 Mar 2017

HAL is a multi-disciplinary open access archive for the deposit and dissemination of scientific research documents, whether they are published or not. The documents may come from teaching and research institutions in France or abroad, or from public or private research centers.
L'archive ouverte pluridisciplinaire HAL, est destinée au dépôt et à la diffusion de documents scientifiques de niveau recherche, publiés ou non, émanant des établissements d'enseignement et de recherche français ou étrangers, des laboratoires publics ou privés. 


\title{
JOINT INTEGRATED PRODUCTION-MAINTENANCE POLICY WITH PRODUCTION PLAN SMOOTHING THROUGH PRODUCTION RATE CONTROL
}

\author{
Sofiene Dellagi \\ LGIPM, Université de Lorraine, Metz, France \\ Email: Sofiene.dellagi@univ-lorraine.fr \\ Anis Chelbi \\ University of Tunis, Ecole Nationale Supérieure d'Ingénieurs de Tunis, CEREP, Tunis, Tunisia \\ Email: anis.chelbi@planet.tn \\ Wajdi Trabelsi \\ LGIPM, ICN Business School, Nancy Metz, France \\ Email: wajdi.trabelsi@icn-groupe.fr
}

\begin{abstract}
We consider a production system that has to satisfy a random demand during a finite planning horizon under a required service level. This study consists in developing an analytical model in order to determine a near-optimal integrated maintenance-production plan which takes into consideration the influence of the production rate on the system's failure rate while attempting in the same time to smooth the production plan through the production rate control between periods of the planning horizon. A numerical example is presented in order to illustrate the contribution of the proposed modelling approach and discuss the different trade-offs that are considered.
\end{abstract}

Key Words: Integrated production-maintenance strategies, Optimization, Variable production rates, Degradation, and Smoothing production rate.

\section{INTRODUCTION AND LITTERATURE REVIEW}

Manufacturing companies must manage several functional areas successfully, such as production, maintenance, quality and marketing. One of the keys to success consists in treating all these services simultaneously. In order to ensure an efficient coordination between them, managers and decision makers have to consider a global systemic approach integrating the interactions between parts or all of those complementary functions. In this perspective, several researchers have investigated ways of integrating maintenance and production after decades during which those two functions had been studied separately. Works on maintenance policies started with Barlow et al. [1] and continued with a huge number of contributions as it can be seen in a survey on maintenance models by Wang [2]. During the last two decades, several companies have realized that strategies dissociating maintenance and production were ineffective. The need for developing new integrated maintenance-production strategies became evident. Brandolese et al. [3] proposed a strategy for maintaining a multiple machines production system. The planning consists in programming the execution date of each task and the machine that should perform it. They integrated preventive maintenance tasks in the planning placing them as close as possible to the optimal maintenance periods. 
Chelbi et al. [4] developed a mathematical model in order to determine both the buffer stock size and the preventive maintenance period for an unreliable production unit which is subject to regular preventive maintenance of random duration. The optimization of the preventive maintenance period and the buffer size was also the problem addressed by Pal et al. [5] in the context of an imperfect production system that may shift to an 'out-of-control' state after a random time. Non-conforming products are reworked incurring an additional cost. They also considered the situation where both the buffer size and the production rate are the decision variables. Rezg et al. [6] developed an analytical model and a numerical procedure which allow determining a joint optimal inventory control and age-based preventive maintenance policy for a randomly failing production system. Recently, Tambe and Kulkarni [7] developed a selective maintenance and quality control decision optimization framework considering the production schedule of the machine. They derive an optimal maintenance decision, consisting in one of three actions (repair, replace or do-nothing) for the system components along with the optimal sample size, the acceptance number and the time between samples, taking into account the optimal production schedule. The authors used a genetic algorithm in order to solve the problem.

In the same framework, some researchers have taken into account several external constraints. In fact, integrated maintenance-production strategies which take into consideration subcontracting have been studied by Dellagi et al. [8]. They developed and optimized a maintenance policy incorporating subcontractor constraints. They demonstrated through a case study, the influence of the subcontractor constraints on the optimal integrated maintenance-production strategy. Dealing also with the same subject, Dahane et al. [9] studied analytically the problem of the integration of subcontracting activities and determined the optimal number of subcontracting tasks to be performed during a maintenance cycle. Recently, Nourelfath et al. [10] dealt also with the same problem of integrating preventive maintenance and production planning, for a production system composed of a set of parallel components. A subsequent work by Nourelfath and Châtelet [11] assumed the presence of economic dependence and common cause failures in the production system. Mifdal et al. [12] considered the same problem in the case of multiple-products manufacturing systems.

Looking at the literature on integrated maintenance-production policies, we noticed that the influence of the production rate on the system degradation in presence of a random demand over a finite planning horizon was rarely addressed in depth. Very few works dealt with this issue. For example, the study of Hajej et al. [13] which presents an analytical stochastic optimization model based on the operational age concept, revealed the significant influence of the production rate on the deterioration of the manufacturing system and consequently on the integrated production-maintenance policy. Later, Hajej et al. [14] dealt with the same problem by integrating a subcontracting constraint in order to recycle a certain quantity of returned products. In these two studies, the authors started by establishing an optimal production plan which minimizes the total inventory and production cost taking into consideration the subcontractor constraint. Then, using this optimal production plan, they derived an optimal maintenance schedule which minimizes the total maintenance cost. Their approach is sequential. Moreover, they do not consider the influence of having differences between quantities produced in successive periods and the impact of such differences on labour and set-up related costs.

The approach adopted in this study favours the fact of smoothing the production rate between periods in order to avoid the disadvantages of a significant variation (mainly in terms of setup costs). 
This paper is organized as follows: In the next section we specify the targeted contributions of this work. Then the problem and the working assumptions are described in section 3. Section 4 is dedicated to the working assumptions and the development of the analytical model. A numerical example is presented in section 5 to illustrate the proposed modelling approach and discuss different trade-offs that are considered. Finally, conclusions and potential future work are provided in Section 6.

\section{TARGETED CONTRIBUTIONS}

Several industries such as steel production exhibit fluctuation of the production rate between production periods. This yields a great deal of set-up and preparation work like unloading and loading raw materials using special equipment and human resources. Moreover, in the case of production lines, generally buffers with finite capacities are present between machines. The variation of the production rate between periods brings the necessity of changing the buffers' levels involving a certain handling and logistics cost. Hence, it is clear that the production rate fluctuation between periods may have a significant impact on the set-up cost incurred at the beginning of each period. To the best of our knowledge, this issue has not been considered in the literature. The adopted approach in this study favors the fact of smoothing the production rate between periods in order to avoid the disadvantages of a significant variation (mainly in terms of set-up costs). We also propose an integrated (and not sequential) optimization of the maintenance schedule and the production plan in order to derive a near-optimal integrated maintenance-production strategy taking into account the penalty induced by excessive variation of the production rate between periods of the planning horizon. To do so, we express the set-up cost as being proportional to the production rate variation between successive periods of the production plan. Besides, we propose new modelling features in the total integrated cost modelling, particularly when dealing with the shortage and inventory holding costs by considering them separately contrarily to the previous studies mentioned above.

The proposed model allows the investigation of different trade-offs. The first one is between the smoothing penalty and the production plan, the inventory, and the preventive maintenance schedule. We also consider the effect of the demand variability on the smoothing penalty, the production and maintenance plans, and on the total expected cost.

\section{PROBLEM STATEMENT}

We consider a single machine $M$ subject to degradation and random failures. It produces one type of product whose demand is random and characterized by a Normal probability distribution with known average and standard deviation. The demand is satisfied from a stock (Fig. 1). Production is planned over a finite horizon divided in $H$ production periods of equal length $\Delta t$. It is assumed that the quantity produced at every period is added to the stock at the end of the period and the demand of every period is satisfied at the end of the period. The machine failure rate increases with both time and the production rate. Periodic preventive maintenance actions have to be scheduled to reduce the probability of failure.

We are in presence of a production control problem with a state variable, namely the inventory level, together with the following control variables: the production rates for every period and the number of preventive maintenance actions to be performed over the time horizon $H \Delta t$. 


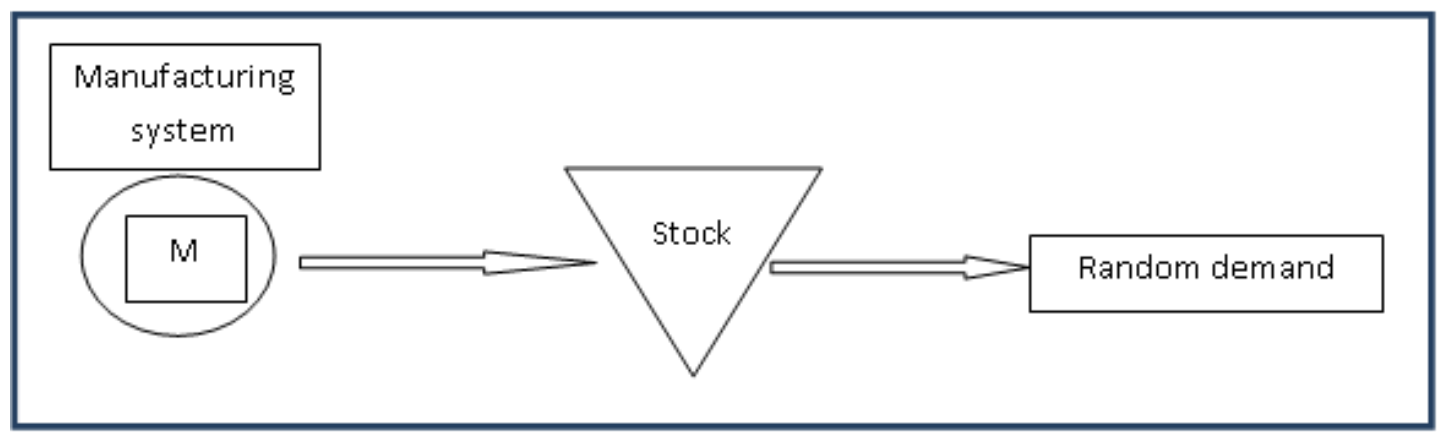

Figure 1: Problem statement

The objective is to minimize the total expected cost over the production planning horizon made of $H$ periods. This cost integrates production costs, inventory and shortage costs, preventive and corrective maintenance costs and an additional cost related to a penalty due to the production rate variation between successive periods.

As it will be shown in next section, compared to previous works dealing with the same subject, the first contribution of this study consists in the total integrated cost modelling. On one hand, the shortage and inventory holding costs are formulated separately, and on the other hand, the average number of failures is modelled differently considering an increasing failure rate according to both time and production rate.

The second feature consists in the integrated (and not sequential) optimization of the production plan and the maintenance schedule taking into account the influence of the production rate variation on the system degradation. Finally, the third main contribution is the control of the production rate variation between successive periods in order to smooth the production plan by reducing the penalty induced by excessive variation of the production rate over the planning horizon.

\section{ANALYTICAL STUDY}

\subsection{Used notation}

The following parameters are used in the mathematical formulation of the model:

$\Delta t:$ length of a production period

$H$ : number of production periods in the planning horizon

$H . \Delta t$ : length of the finite planning horizon

$z(p)$ : produced quantity during period $p(p=1, \ldots, H)$

$z_{\max }:$ maximum quantity that can be produced during period $\mathrm{p}$

$\boldsymbol{Z}=\{z(1), \ldots z(p), \ldots, z(H)\}$ : Production plan over the horizon $H . \Delta t$

$u(p)$ : production rate of the system during period $p(p=1, \ldots, H) ;(u(p)=z(p) / \Delta t)$

$u_{\text {max }}:$ maximum production rate of the system $($ umax $=\mathrm{zmax} / \Delta \mathrm{t})$

$\boldsymbol{U}=\{u(1), \ldots u(p), \ldots, u(H)\}:$ Set of production rates adopted for each period

$d(p)$ : average demand during period $p(p=1, \ldots, H)$

$V$ : variance of demand for all periods $p(p=1, \ldots, H)$

$\sigma:$ standard deviation of demand for all periods

$S(p)$ : inventory level at the end of period $\mathrm{p}$

$S_{0}$ : the inventory level at the start of period 1

$C_{p r}$ : unit production cost 
Cs : inventory holding cost of one product unit per time unit.

$\mathrm{Cl}$ : shortage cost of one product unit.

$C T S$ : expected total cost of production, shortage and inventory holding over the time horizon $H \Delta t$

$C_{v}:$ unit set-up cost

$C M$ : total average maintenance cost

$C_{p m}$ : preventive maintenance action cost

$C_{c m}$ : corrective maintenance action cost

$S C$ : penalty cost relative to production rate variation

$m u:$ monetary units

$\theta:$ probability to satisfy the demand (service level).

$f(t)$ : probability density function associated with the time to failure of $M$

$F(t)$ : probability distribution function associated with the time to failure of $M$

$R(t)$ : reliability function: $1-F(t)$

$\lambda_{n}(t)$ : nominal failure rate corresponding to the maximum production rate (depends only on time)

$\lambda(t, u(p))$ : machine failure rate function during period $p(p=1, \ldots, H)$ (depends on time and on the production rate during period $p$ )

$t u$ : time units

The cost model to be developed corresponds to a production/maintenance planning problem with constraints related to inventory, production and preventive maintenance.

\subsection{Woking Assumptions}

The following assumptions are considered:

- The machine failure rate increases with both time and production rate

- Preventive maintenance actions restore the machine to an "as-good-as-new" state.

- The planning time horizon starts with a new or as good as new machine. However, it doesn't end necessarily with a perfect preventive maintenance action. The equipment could be replaced by a different one or maintained differently after the end of the planning period.

- The quantity $z(p)$ produced in period $p$ is added to the inventory at the end of the period and then the demand $d(p)$ is satisfied.

- Preventive maintenance and repair actions durations are negligible.

- The units short are lost (no backorders) and a shortage cost is incurred.

\subsection{Formulation of the integrated production-maintenance total expected cost}

We develop in what follows the expressions of the three major components of the total expected cost incurred over the planning horizon. These costs are: the production and inventory cost, the maintenance cost, and the set-up cost (smoothing penalty). Recall that the decision variables are the production rates for every period and the number of preventive maintenance actions to be performed over the planning horizon.

\subsubsection{Production, shortage and inventory costs formulation}

The constraints related to inventory balance, service level satisfaction, and maximum production quantity per period, are expressed as follows: 
Inventory balance:

$$
S(p+1)=S(p)+z(p+1)-d(p+1) \quad \forall p=0, \ldots ., H-1
$$

With: $S(1)=S_{0}+z(1)-d(1)$

Service level satisfaction:

$$
\operatorname{Prob}[S(p+1) \geq 0] \geq \theta \quad \forall p=0, \ldots, H-1
$$

Production capacity:

$$
0 \leq z(p) \leq z_{\max } \quad \forall p=1, \ldots, H
$$

Accordingly, the inventory evolves as shown in the example below in Fig. 2:

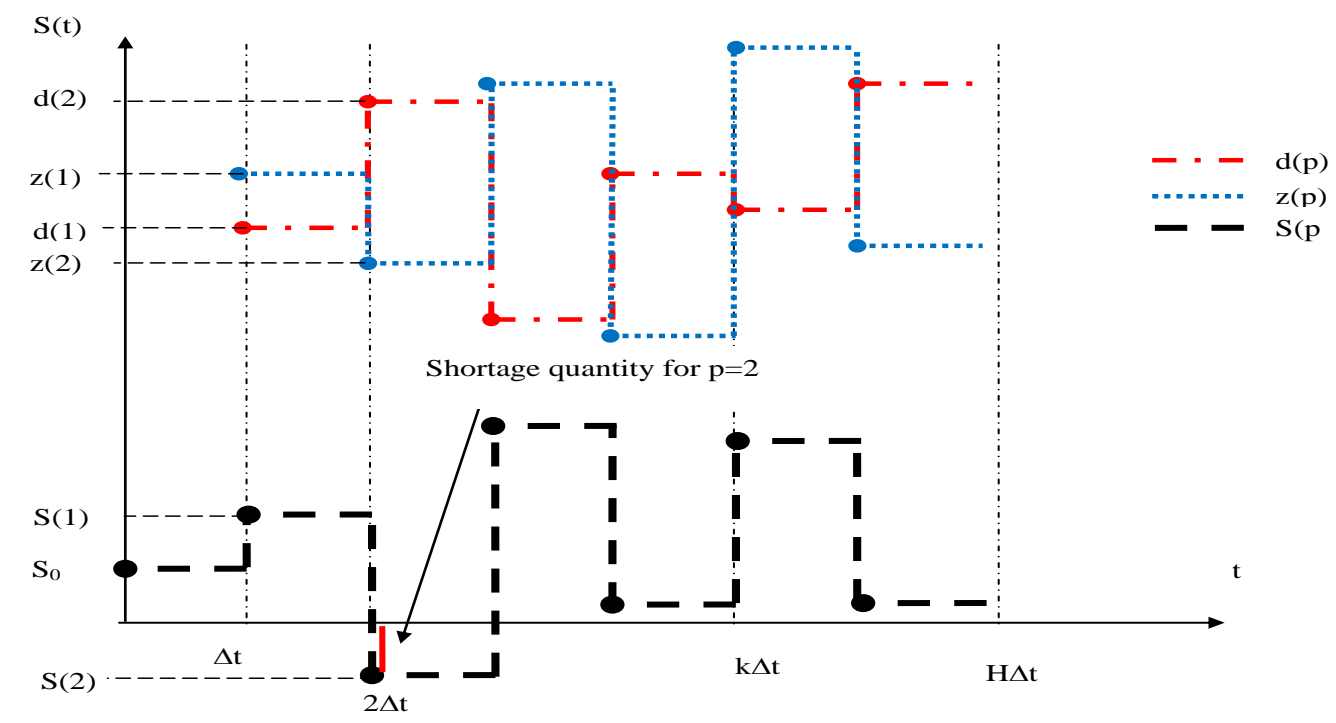

Figure 2: Inventory evolution over the planning horizon $H \Delta t$

Thus, the expression of the total cost of production, shortage and inventory over the finite horizon $H \Delta t$ is given by:

$$
C T S=\left(C s \times \Delta t \times \sum_{p=1}^{H}\left(S(p) \times 1_{S(p)>0}\right)\right)+\left(C l \times \sum_{p=1}^{H}\left(|S(p)| \times 1_{S(p)<0}\right)\right)+\left(C_{p r} \times \sum_{p=1}^{H} z(p)\right)
$$

With: $1_{S(p)>0}$ is equal to 1 if $S(p)>0$ and equal to zero otherwise

$1_{S(p)<0}$ is equal to 1 if $S(p)<0$ and equal to zero otherwise

It is worth noticing here that most of the papers dealing with the same subject such as Hajej et al. [13,14,15] and Ayed et al. [16] consider a quadratic model (known as HMMS (Holt, Madigliani, Muth, and Simon) [17]) integrating shortage and excess of stock considering however the same unitary cost for shortage and for inventory holding. 
Our approach (Eq. 4) makes this important distinction between these unitary costs that are not the same in practice.

The constraint relative to the service level is stochastic. It is possible to transform this constraint to a deterministic one (Hajej et al. [13]). In fact, it provides the minimal quantities to produce at each period $p$ in order to satisfy the service level.

$$
\operatorname{Prob}[S(p+1) \geq 0] \geq \theta \quad \Rightarrow \quad z(p+1) \geq z_{(S(p), \theta)} \quad \forall p \in\{0, \ldots, H-1\}
$$

Where $z_{(S(p), \theta)}$ represents a minimum cumulative production quantity expressed as follows:

$$
z_{(S(p), \theta)}=\left(\left(\phi_{p+1}\right)^{-1}(\theta)\right) \times V_{p+1}+d(p+1)-S(p) \quad \forall p \in\{0, \ldots, H-1\}
$$

With:

$V_{p+1}$ : variance of demand at period $p+1$;

$\Phi_{p+1}$ : cumulative Gaussian distribution function with mean $d(p+1)$ and finite variance $V_{p+1}$. $\Phi_{p+1}^{-1}$ : inverse Gaussian distribution function

\subsubsection{The maintenance cost formulation}

We consider a periodic preventive maintenance $(P M)$ policy with minimal repair at failure. The interval $[0, H \Delta t]$ is partitioned into $N$ equal parts each of length $k \Delta t$ plus a possible remaining duration shorter than $k \Delta t$. Perfect preventive maintenance actions are performed periodically at times $i \times k \Delta t, i=1, \ldots, N$.

For a given production plan $\boldsymbol{Z}(\boldsymbol{Z}=\{z(1), \ldots, z(p), \ldots, z(H)\})$, and a given $P M$ period $k \Delta t$, the total maintenance cost is given by:

$$
C M(U, k)=C_{p m} \times N(k)+C_{c m} \times \varphi(U, k)
$$

$N(k)$ represents the integer part of $(H / k)$, which corresponds to the number of $P M$ actions. $k$ is the decision variable through which the maintenance policy can be defined. $\varphi(U, k)$ stands for the average number of failures (minimal repairs) over the horizon $H \Delta t$.

The lemma below provides the expression of the average number of failures:

\section{Lemma}

$$
\begin{aligned}
& \varphi(U, k)=\sum_{j=0}^{N(k)-1}\left[\int_{0}^{\Delta t} \frac{u_{1 j}}{u_{\max }} \lambda_{n}(t) d t+\sum_{i=2}^{k}\left[\int_{0}^{\Delta t} \frac{u_{i j}}{u_{\max }} \lambda_{n}(t) d t+(k-(i-1))\left(\frac{u_{(i-1) j}}{u_{\max }} \lambda_{n}(\Delta t) \times \Delta t\right)\right]\right] \\
& +\left[\int_{0}^{\Delta t} \frac{u_{1 N(k)}}{u_{\max }} \lambda_{n}(t) d t\right] \times\left(1_{(H-N(k) \times k)=1}\right) \\
& +\left[\left[\int_{0}^{\Delta t} \frac{u_{1 N(k)}}{u_{\max }} \lambda_{n}(t) d t\right]+\sum_{i=2}^{H-N(k) \times k}\left[\int_{0}^{\Delta t} \frac{u_{i N(k)}}{u_{\max }} \lambda_{n}(t) d t+(k-(i-1))\left(\frac{u_{(i-1) N(k)}}{u_{\max }} \lambda_{n}(\Delta t) \times \Delta t\right)\right] \times\left(1_{(H-N(k) \times k)>1}\right)\right.
\end{aligned}
$$

$u_{i j}$ represents the production rate during period $i$ after the $j^{\text {th }} P M$ action. 


\section{Proof}

Recall that $P M$ actions are performed every $k$ production periods, which means every $k \Delta t$ restoring the system to as good as new state.

The planning horizon $H \Delta t$ is divided into $(N(k)+1)$ periods, each one is noted $j, j \in\{0,1,2 \ldots$. $,(N(k))\}$. Hence, $j=0$ corresponds to the first $P M$ interval $[0, k \Delta t]$, the second $P M$ period $[k \Delta t$, $2 k \Delta t]$ corresponds to period $j=1$, etc. Note that the last $P M$ action is performed at instant $(N(k) \cdot k \cdot \Delta t)$, and the interval $[(N(k)-1) \cdot k \cdot \Delta t),(N(k) \cdot k \cdot \Delta t)]$ corresponds to $j=(N(k)-1)$.

To illustrate this decomposition, Fig. 3 below shows an example with the following values: $H=13$ periods; $k=3$ periods, $N=4, \Delta t=1 t u$. Hence, $N(k)=4 .(N(k) \cdot k \cdot \Delta t)=12 t u$.

o

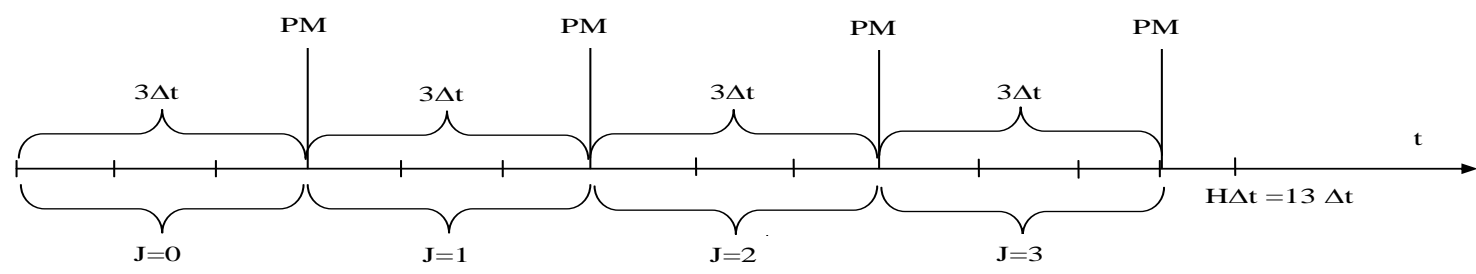

Figure 3: Example of PM periods over a planning horizon $H \Delta t=13$ time units

The average number of failures over the planning horizon $H . \Delta t$ is the sum of the average number of failures during periods $j=0$ to $(N(k)-1)$, to which should be added the average number of failures during the last interval $[(N(k) . k . \Delta t, H \Delta t]$ corresponding to $\mathrm{j}=(N(k))$.

\section{Average number of failures during a $P M$ period $j$}

Recall that the system failure rate evolves according to time and to the production rate which varies from one period to another. In order to take into account the influence of the production rate variation on the system degradation, we use Cox model [18]. Formally, the failure rate is expressed according to the production rate during each period and the nominal failure rate. The following expression is proposed (Hajej et al. [13]):

$$
\lambda_{p}(t, u(p))=\lambda_{n}(t) \times g(u(p))
$$

Where $\lambda_{p}(t, u(p))$ represents the instantaneous failure rate function at period $p$ as a function of the production rate $u(p) . \lambda_{n}(t)$ is the failure rate for nominal conditions which corresponds to the failure rate when the production system is operating with its maximum production rate, and $g(u(p))=\frac{u(p)}{u_{\max }}$.

Although this linear relationship between the production rate and the failure rate does not necessarily hold for any type of systems, it is adopted here like in (Hajej et al. [13], [14], [15]) as an approximation.

Let $u_{i j}$ represent the production rate during period $i$ after the $j^{\text {th }} P M$ action.

$u_{i j} \quad$ with $\quad(i, j) \in(\{1, \ldots, k\},\{0, \ldots, N(k)\})$

Hence, the failure rate during period $i$ after the $j^{\text {th }} P M$ action is given by:

$$
\lambda_{i j}\left(t, u_{i j}\right)=\lambda_{n}(t) \frac{u_{i j}}{u_{\max }} \quad \forall \quad(i, j) \in(\{1, \ldots, k\},\{0, \ldots, N(k)\})
$$


The evolution of the production system's failure rate within any preventive maintenance cycle period $j=h$ is presented in Fig. 4 below:

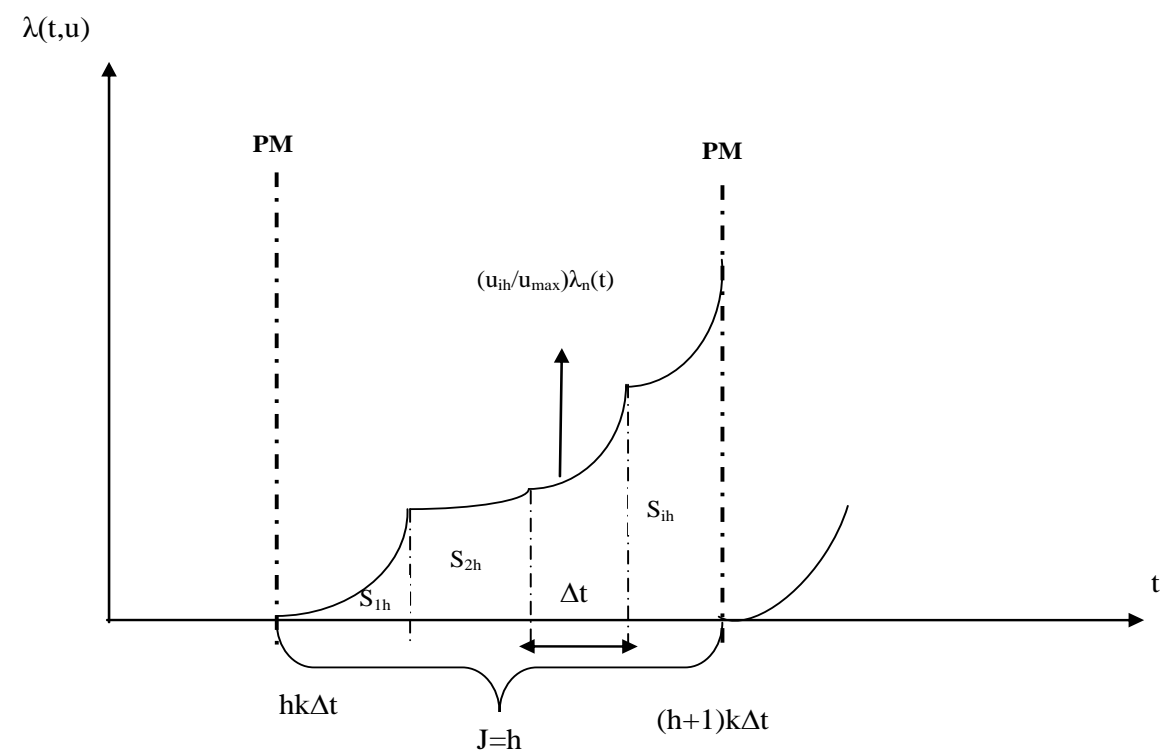

Figure 4: Evolution of the production system failure rate within a preventive maintenance cycle $($ period $j=h)$

Let $S_{1 j}$ be the average number of failures during the first production period after the $j^{\text {th }} P M$ action:

$$
S_{1 j}=\int_{0}^{\Delta t} \frac{u_{1 j}}{u_{\max }} \lambda_{n}(t) d t
$$

In the same way, $S_{2 j}$, corresponding to the average number of failures during the second production period after the $j^{\text {th }} P M$ action, is given by:

$$
S_{2 j}=\int_{0}^{\Delta t} \frac{u_{2 j}}{u_{\max }} \lambda_{n}(t) d t+\left(\frac{u_{1 j}}{u_{\max }} \lambda_{n}(\Delta t) \times \Delta t\right)
$$

Generalizing this to all production periods after the $j^{\text {th }} P M$ actions, we obtain:

$$
S_{i j}=\int_{0}^{\Delta t} \frac{u_{i j}}{u_{\max }} \lambda_{n}(t) d t+(k-(i-1))\left(\frac{u_{(i-1) j}}{u_{\max }} \lambda_{n}(\Delta t) \times \Delta t\right) \quad \text { for } i \in\{2,3 \ldots k\}
$$

Hence, the average number of failures during any period $j$ is expressed as follows: 


$$
\int_{0}^{\Delta t} \frac{u_{1 j}}{u_{\max }} \lambda_{n}(t) d t+\sum_{i=2}^{k}\left[\int_{0}^{\Delta t} \frac{u_{i j}}{u_{\max }} \lambda_{n}(t) d t+(k-(i-1))\left(\frac{u_{(i-1) j}}{u_{\max }} \lambda_{n}(\Delta t) \times \Delta t\right)\right] \quad \forall \quad j \in\{0, \ldots, N(k)\}
$$

Average number of failures over the period $[0,(N(k) . k . \Delta t]$

Considering all periods $j(j=0$ to $N(k)-1)$, the total average number of failures over the interval $[0,(N(k) . k . \Delta t]$ is expressed as follows:

$$
\sum_{j=0}^{N(k)-1}\left[\int_{0}^{\Delta t} \frac{u_{1 j}}{u_{\max }} \lambda_{n}(t) d t+\sum_{i=2}^{k}\left[\int_{0}^{\Delta t} \frac{u_{i j}}{u_{\max }} \lambda_{n}(t) d t+(k-(i-1))\left(\frac{u_{(i-1) j}}{u_{\max }} \lambda_{n}(\Delta t) \times \Delta t\right)\right]\right]
$$

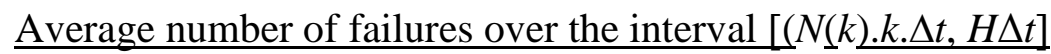

Looking at the remaining period $[N(k) \cdot k . \Delta t, H \Delta t]$ after the last $P M$ action is performed during the planning horizon, one can distinguish three possible cases:

- Case 1: this period doesn't exist. This means that the last preventive maintenance action coincides with $\mathrm{H}$. $\Delta \mathrm{t}$, the end of the planning horizon.

Formally: $H-(N(k) \cdot k)=0$

- Case 2: we have only one production period of length $\Delta \mathrm{t}$, in the interval $[N(k) \cdot k . \Delta t, H \Delta t]$. Formally: $H-(N(k) \cdot k)=1$

- Case 3: we have more than one production period in the interval $[N(k) . k . \Delta t, H \Delta t]$. Formally: $H-\left(N(k)^{*} k\right)>1$

Taking into account these three possible situations, the average number of failures in the interval $[N(k) \cdot k \cdot \Delta t, H \Delta t]$ is given by:

$$
\begin{aligned}
& {\left[\int_{0}^{\Delta t} \frac{u_{1 N(k)}}{u_{\max }} \lambda_{n}(t) d t\right] \times\left(1_{(H-N(k) \times k)=1}\right)} \\
& +\left[\left[\int_{0}^{\Delta t} \frac{u_{1 N(k)}}{u_{\max }} \lambda_{n}(t) d t\right]+\sum_{i=2}^{H-N(k) \times k}\left[\int_{0}^{\Delta t} \frac{u_{i N(k)}}{u_{\max }} \lambda_{n}(t) d t+(k-(i-1))\left(\frac{u_{(i-1) N(k)}}{u_{\max }} \lambda_{n}(\Delta t) \times \Delta t\right)\right]\right] \times\left(1_{(H-N(k) \times k)>1}\right)
\end{aligned}
$$

The first term of this sum corresponds to case 2, and the second and third terms correspond to case 3. Obviously, in the first case (case 1), the number of failures is equal to zero.

\section{Average number of failures over the planning horizon $H . \Delta t$}

Summing up the obtained average number of failures for all periods, we obtain: 


$$
\begin{aligned}
& \varphi(\boldsymbol{U}, k)=\sum_{j=0}^{N(k)-1}\left[\int_{0}^{\Delta t} \frac{u_{1 j}}{u_{\max }} \lambda_{n}(t) d t+\sum_{i=2}^{k}\left[\int_{0}^{\Delta t} \frac{u_{i j}}{u_{\max }} \lambda_{n}(t) d t+(k-(i-1))\left(\frac{u_{(i-1) j}}{u_{\max }} \lambda_{n}(\Delta t) \times \Delta t\right)\right]\right] \\
& +\left[\int_{0}^{\Delta t} \frac{u_{1 N(k)}}{u_{\max }} \lambda_{n}(t) d t\right] \times\left(1_{(H-N(k) \times k)=1}\right) \\
& +\left[\left[\int_{0}^{\Delta t} \frac{u_{1 N(k)}}{u_{\max }} \lambda_{n}(t) d t\right]+\sum_{i=2}^{H-N(k) \times k}\left[\int_{0}^{\Delta t} \frac{u_{i N(k)}}{u_{\max }} \lambda_{n}(t) d t+(k-(i-1))\left(\frac{u_{(i-1) N(k)}}{u_{\max }} \lambda_{n}(\Delta t) \times \Delta t\right)\right]\right] \times\left(1_{(H-N(k) \times k)>1}\right)
\end{aligned}
$$

End of the proof

\subsection{Penalty cost relative to the production rate variation: variable set-up cost}

As mentioned earlier, one of the objectives of this study is to smooth the production rate between periods. To do so, we consider a variable set-up cost, which is proportional to the difference of the quantity produced from one period to the next one. Indeed, reducing or increasing the quantity to produce may induce in many situations labour related costs (overtime, or hiring/firing costs) and more or less complexity of the set-up.

We define $C_{v}$ as unit set-up cost. It corresponds to the direct cost of resources needed to adapt the production unit to the production quantity change between successive periods.

Hence, the penalty cost relative to production rate variation is given by:

$$
S C=C_{v} \times \sum_{p=1}^{H-1}|z(p+1)-z(p)|
$$

\subsection{The total integrated maintenance/ production/inventory cost taking into account the set up cost}

Using the developed mathematical expressions above in this section, the total cost optimization problem can be formulated as follows:

$$
\underset{(\boldsymbol{Z}, k)}{\operatorname{Min}}(C T S+C M+S C)
$$

Subject to:

$$
\begin{array}{cc}
S(p+1)=S(p)+z(p+1)-d(p+1) & \forall p=0, \ldots, H-1 \\
\operatorname{Prob}[S(p+1) \geq 0] \geq \theta & \forall p=0, \ldots, H-1 \\
0 \leq z(p) \leq z_{\max } & \forall p=1, \ldots, H
\end{array}
$$

\subsection{Solution method}

Formally, solving the constrained minimization problem stated above (Eq. 10), yields the determination of optimal production quantity for every period $\left\{z(1)^{*}, z(2)^{*}, \ldots, z(p)^{*}, \ldots\right.$, $\left.z(H)^{*}\right\}$ and the optimal period $\left(k^{*} \Delta t\right)$ of $P M$ actions to be performed over the finite horizon $H \Delta t$. Due to the obvious complexity of the model, we developed an iterative search procedure to find a near-optimal solution. It is presented below in four steps. 
- Step 1: Use Eqs. (5) and (6) to determine the minimum cumulative production quantity to produce in each period in order to satisfy the service level constraint given by Eq. (2).

- Step 2: Perform a simple enumeration by varying the production quantity for each period $p$ (using a relatively small step) between the minimum value obtained in step 1 and the maximum one $z_{\max }$ given in constraint (3) in order to consider all possible production plans.

- Step 3: For every production plan established in step 2, vary $k$, number of production periods between preventive maintenance actions, between 1 and $H$, and calculate each time the corresponding total cost (Eq. 10).

- Step 4: Determine the values of the decision variables $\left(\left(z(1)^{*}, z(2)^{*}, \ldots z(p)^{*}, \ldots, z(H)^{*}\right)\right.$, $\left.k^{*}\right)$ which yielded the minimal total cost.

MATHEMATICA $^{\circledR}$ software was used to perform the calculations and obtain a near-optimal solution for all instances of the problem considered in this paper.

\section{NUMERICAL EXAMPLE AND TRADE-OFFS ANALYSIS}

\subsection{Reference example}

A numerical example is presented in this section in order to illustrate the use of the analytical model developed in the previous sections. We assume that the finite planning horizon is made of 36 periods of one month each $(\Delta t=1$ month). The other input data are summarized in Table 1 below (' $m u$ ' stands for 'monetary units):

\begin{tabular}{|c|c|}
\hline \multicolumn{2}{|l|}{ Reliability data } \\
\hline System time to failure distribution & $\begin{array}{l}F(t): \text { Weibull distribution with : } \\
\text { Scale parameter }: \beta=16 \& \text { Shape parameter }: \alpha=3\end{array}$ \\
\hline Corrective maintenance cost & $C_{c m}=3000 \mathrm{mu}$ \\
\hline Preventive maintenance cost & $C_{p m}=500 \mathrm{mu}$ \\
\hline \multicolumn{2}{|l|}{ Inventory data } \\
\hline Shortage cost per unit & $\mathrm{Cl}=1 \mathrm{mu} /$ unit short \\
\hline Inventory holding cost per unit per time unit & $C s=0.65 \mathrm{mu} / \mathrm{unit} / \mathrm{tu}$ \\
\hline Initial inventory level & $S(0)=0$ \\
\hline Service level & $\theta=0.9$ \\
\hline \multicolumn{2}{|l|}{ Production data } \\
\hline Unit production cost & $C_{p r}=7 \mathrm{mu} / \mathrm{unit}$ \\
\hline $\begin{array}{l}\text { Maximum production rate } \\
\text { Maximum production quantity per period }\end{array}$ & $\begin{array}{l}u_{\max }=500 \text { units per month } \\
z_{\max }=500 \text { units }\end{array}$ \\
\hline Nominal set-up cost & $C_{v}=5 \mathrm{mu}$ \\
\hline
\end{tabular}

Table 1: Numerical data 
As for the demand, the variance is supposed to be equal for all periods: $V=4.52$. The average demand per period is presented in Table 2 below:

\begin{tabular}{|l|l|l|l|l|l|l|l|l|l|l|l|}
\hline Jan & Feb & Mar & Apr & May & Jun & Jul & Aug & Sep & Oct & Nov & Dec \\
\hline 350 & 420 & 340 & 392 & 431 & 444 & 442 & 340 & 392 & 375 & 392 & 400 \\
\hline 350 & 370 & 395 & 415 & 431 & 444 & 442 & 340 & 392 & 375 & 400 & 420 \\
\hline 350 & 340 & 392 & 370 & 431 & 392 & 500 & 350 & 320 & 420 & 365 & 480 \\
\hline
\end{tabular}

Table 2: Monthly mean demand

Solving the problem using the procedure described in section 3 , we obtain the following nearoptimal maintenance/production plan presented in Table 3 below:

\begin{tabular}{|c|c|c|c|c|c|c|c|c|c|c|c|c|c|}
\hline \multicolumn{10}{|c|}{ Near-optimal production plan over the finite horizon $H \Delta t=36$ months } & $N^{*}$ & $k^{*}$ \\
\hline Jan & Feb & Mar & Apr & May & Jun & Jul & Aug & Sep & Oct & Nov & Dec & & \\
\hline 500 & 500 & 439 & 500 & 500 & 269 & 434 & 352 & 500 & 500 & 395 & 470 & & \\
\hline 500 & 438 & 485 & 400 & 400 & 127 & 400 & 500 & 465 & 193 & 400 & 370 & 6 \\
\hline 65 & 438 & 500 & 200 & 400 & 400 & 499 & 323 & 407 & 351 & 166 & 400 & & \\
\hline
\end{tabular}

$N^{*}$ : Optimal number of preventive maintenance actions over $H \Delta t$

$k^{*}$ : Optimal number of production periods between preventive maintenance actions

Table 3: Near-optimal maintenance/production plan

The total cost related to this plan is equal to : $5.24429 \times 10^{7} \mathrm{mu}$.

\subsection{Sensitivity analyses}

- Effect of $C_{v}$ on the production plan, the inventory, and the preventive maintenance schedule

In the perspective of smoothing the production plan through the production rate control between periods of the planning horizon, we studied the impact of the variation of the unit set-up cost between successive periods, $C v$, on the obtained solution.

Considering the same input data, we obtained the following results presented in Table 4: 


\begin{tabular}{|c|c|c|c|c|}
\hline $\begin{array}{c}C_{v}: \text { Unit set-up cost } \\
\text { between successive } \\
\text { periods }\end{array}$ & $\begin{array}{c}\text { Average production quantity } \\
\text { variation between successive } \\
\text { periods }\end{array}$ & $N^{*}$ & $k^{*}$ & $\begin{array}{c}\text { Average end of } \\
\text { month inventory }\end{array}$ \\
\hline 2 & 143.71 & 6 & 6 & 156.94 \\
\hline 5 & 126.17 & 7 & 5 & 464.56 \\
\hline 7 & 75.31 & 7 & 5 & 1200.53 \\
\hline 8 & 74.57 & 9 & 4 & 1221.47 \\
\hline 10 & 58.34 & 458.58 \\
\hline
\end{tabular}

Table 4: Effect of the variation of the unit set-up cost

Fig. 5 below shows the trade-off between the unit-setup cost and the average production quantity variation between successive periods, the optimal number of preventive maintenance actions, and the average end of month inventory.

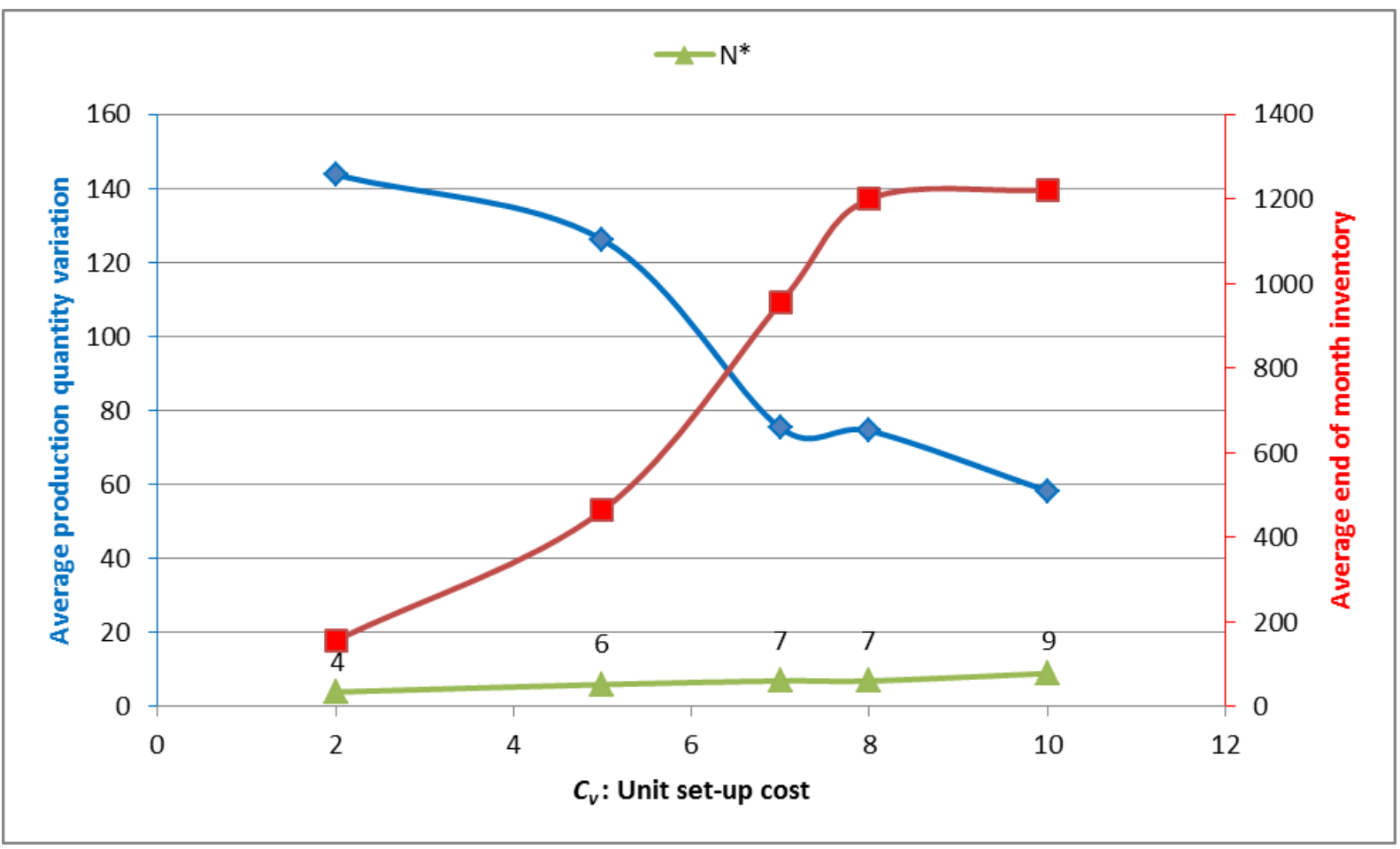

Figure 5: Evolution of the average production quantity variation between successive periods, and the average end of month inventory according to the unit set-up $\operatorname{cost} C_{v}$

First, one can easily notice that, as expected, when the unit set-up cost between successive periods increases, the average variation of the production quantity, between successive periods, decreases. This clearly illustrates the effect of production smoothing. 
Furthermore, it is interesting to notice that the decrease of the average variation of the production quantity between successive periods yields an increase of the quantity to be produced in some periods, and consequently a higher average end of month inventory. Indeed, we know that the quantity to be produced in each period should be between a certain minimum given by the service level constraint (Eqs. 5 and 6) and a given maximum corresponding to the capacity of the machine (Eq. 3). These limits are considered in the first two steps of the solving procedure. Hence, as the smoothing penalty increases, reducing the average variation of the production quantity between successive periods can be achieved either by increasing or by decreasing successive production quantities between the two limits. This is achieved using the model considering simultaneously the trade-off between inventory and shortage costs. The near-optimal solutions, for this specific example, display an increase of the quantities to be produced and therefore an increase of the average end of month inventory. In the same time, the increase of the production rate through the production periods affects the system degradation and induces the need for a more frequent preventive maintenance as it can also be seen in Fig. 5.

The above observations illustrate the fact that the developed model allows the simultaneous consideration of the different trade-offs between the smoothing penalty, the production plan, the inventory, and the preventive maintenance schedule.

We performed several other numerical experiments with different input parameters settings to check the smoothing effect. We present below a sample of the obtained results corresponding to a situation involving a higher shortage cost. While keeping the original combination of input parameters, we increased the shortage cost $C l$ from $1 \mathrm{mu}$ to $5 \mathrm{mu}$. A priori, for such a situation, the quantities to be produced should be higher throughout the production periods since shortages are more costly while production and inventory holding costs remain the same.

The following near-optimal maintenance/production plan has been obtained (Table 5):

\begin{tabular}{|r|c|c|c|c|c|c|c|c|c|c|c|c|c|}
\hline \multicolumn{10}{|c|}{ Near-optimal production plan over the finite horizon $H \Delta t=36$ months } & $N^{*}$ & $k^{*}$ \\
\hline Jan & Feb & Mar & Apr & May & Jun & Jul & Aug & Sep & Oct & Nov & Dec & & \\
\hline 500 & 500 & 392 & 422 & 481 & 500 & 500 & 500 & 500 & 444 & 481 & 404 & \\
\hline 388 & 500 & 322 & 321 & 443 & 132 & 434 & 480 & 467 & 500 & 438 & 500 & 7 & 5 \\
\hline 437 & 330 & 500 & 500 & 479 & 377 & 0 & 500 & 450 & 500 & 500 & 200 & & \\
\hline
\end{tabular}

Table 5: Near-optimal maintenance/production plan with $C l=5 \mathrm{mu}$ and $C v=5 \mathrm{mu}$

The total cost related to this near-optimal plan is equal to : $7.38 \times 10^{8} \mathrm{mu}$.

Compared to the situation with a lower shortage cost $(\mathrm{Cl}=1 \mathrm{mu})$, one can easily observe comparing Tables 3 and 5 that, in total, more products are produced in the second situation (a total of 15782, compared to a total of 14186 items). Moreover, this increase of total production over the same horizon yielded an increase of the number of preventive maintenance actions that have to be performed (from 6 to 7 actions). This is due to the fact that the machine failure rate increases with the production rate. 
Again, in this situation, we studied the impact of the smoothing penalty on the optimal strategy and on the inventory.

The following results were obtained (Table 6):

\begin{tabular}{|c|c|c|c|c|}
\hline $\begin{array}{c}C_{v}: \text { Unit set-up cost } \\
\text { between successive } \\
\text { periods }\end{array}$ & $\begin{array}{c}\text { Average production quantity } \\
\text { variation between successive } \\
\text { periods }\end{array}$ & $N^{*}$ & $k^{*}$ & $\begin{array}{c}\text { Average end of } \\
\text { month inventory }\end{array}$ \\
\hline 2 & 116.74 & 4 & 9 & 592.22 \\
\hline 5 & 75.14 & 7 & 5 & 950.42 \\
\hline 8 & 63.97 & 7 & 5 & 967.5 \\
\hline 10 & 60 & 9 & 4 & 1296.22 \\
\hline
\end{tabular}

Table 6: Effect of the variation of the unit-setup cost with $\mathrm{Cl}=5 \mathrm{mu}$

One can easily notice the same trade-offs as in the case of $(\mathrm{Cl=1} \mathrm{mu})$ discussed above. The increase of $C v$ induces a decrease of the average production quantity variation between successive periods, the need for more preventive maintenance (higher $N^{*}$ ) and the increase of inventory.

- Effect of demand variability on the production and maintenance plans, and on the total expected cost

While keeping the original set of input parameters (Table 1) as well as the monthly average demand (Table 2), we ran experiments varying the demand variance. The following nearoptimal maintenance/production plans have been obtained (Tables 7, 8 and 9):

\begin{tabular}{|c|c|c|c|c|c|c|c|c|c|c|c|c|c|}
\hline \multicolumn{12}{|c|}{ Near-optimal production plan over the finite horizon $\mathrm{H} \Delta \mathrm{t}=36$ months } & $N^{*}$ & $k^{*}$ \\
\hline Jan & Feb & Mar & Apr & $\mathrm{Ma}$ & Jun & Jul & Aug & Sep & Oct & Nov & Dec & \multirow{4}{*}{7} & \multirow{4}{*}{5} \\
\hline 500 & 500 & 439 & 500 & 500 & 369 & 434 & 352 & 500 & 500 & 395 & 470 & & \\
\hline 500 & 438 & 485 & 500 & 500 & 127 & 490 & 500 & 465 & 393 & 500 & 370 & & \\
\hline 365 & 438 & 500 & 200 & 500 & 500 & 499 & 323 & 407 & 351 & 366 & 500 & & \\
\hline
\end{tabular}

Table 7: Near-optimal maintenance/production plan with demand variance $V=8$ 


\begin{tabular}{|c|c|c|c|c|c|c|c|c|c|c|c|c|c|}
\hline \multicolumn{12}{|c|}{ Near-optimal production plan over the finite horizon $\mathrm{H} \Delta \mathrm{t}=36$ months } & $N^{*}$ & $k^{*}$ \\
\hline Jan & Feb & Mar & Ap & May & Jun & Jul & Aug & Sep & Oct & Nov & Dec & \multirow{4}{*}{7} & \multirow{4}{*}{5} \\
\hline 500 & 500 & 500 & 500 & 500 & 500 & 500 & 500 & 449 & 500 & 305 & 500 & & \\
\hline 500 & 500 & 500 & 500 & 500 & 500 & 500 & 500 & 500 & 500 & 500 & 500 & & \\
\hline 500 & 500 & 500 & 500 & 500 & 500 & 500 & 377 & 269 & 318 & 500 & 500 & & \\
\hline
\end{tabular}

Table 8: Near-optimal maintenance/production plan with demand variance $V=10$

\begin{tabular}{|c|c|c|c|c|c|c|c|c|c|c|c|c|c|}
\hline \multicolumn{12}{|c|}{ Near-optimal production plan over the finite horizon $\mathrm{H} \Delta \mathrm{t}=36$ months } & $N^{*}$ & $k^{*}$ \\
\hline Jan & Feb & Mar & Ap & May & Jun & Jul & Aug & Sep & Oct & Nov & Dec & \multirow{4}{*}{12} & \multirow{4}{*}{3} \\
\hline 500 & 500 & 500 & 500 & 500 & 500 & 500 & 500 & 500 & 500 & 500 & 500 & & \\
\hline 500 & 500 & 500 & 500 & 500 & 500 & 500 & 500 & 500 & 500 & 500 & 500 & & \\
\hline 500 & 500 & 500 & 500 & 500 & 500 & 500 & 500 & 500 & 500 & 500 & 500 & & \\
\hline
\end{tabular}

Table 9: Near-optimal maintenance/production plan with demand variance $V=20$

We summarize the obtained results $V$ in table 10 below:

\begin{tabular}{|c|c|c|c|c|c|}
\hline $\begin{array}{c}V: \text { Demand } \\
\text { Variance }\end{array}$ & $N^{*}$ & $k^{*}$ & $\begin{array}{c}\text { Average production quantity } \\
\text { variation between successive } \\
\text { periods }\end{array}$ & $\begin{array}{c}\text { Average end of } \\
\text { month inventory }\end{array}$ & $\begin{array}{c}\text { Total Cost } \\
(\mathrm{mu})\end{array}$ \\
\hline 4.52 & 6 & 6 & 126.17 & 464.56 & $5.25 \times 10^{7}$ \\
\hline 8 & 7 & 5 & 90.8 & 987.33 & $5.77 \times 10^{7}$ \\
\hline 10 & 7 & 5 & 27.25 & 1741.83 & $6.07 \times 10^{7}$ \\
\hline 20 & 12 & 3 & 0 & 1980.25 & $6.57 \times 10^{7}$ \\
\hline
\end{tabular}

Table 10: Effect of the variation of the demand

One can clearly see that a demand with a higher variability causes the system to produce more and generate higher levels of inventory. Hence, because of higher production rates yielding a faster degradation of the machine, more frequent preventive maintenance is needed $\left(N^{*}\right.$ increases). We also note that higher variability of demand yields an increase of the total expected cost.

In fact, as the demand variance increases, obviously, the minimum quantity determined in Step 1 increases in order to satisfy the required service level. The system is then forced to 
produce more per period without exceeding the machine capacity. Here comes the trade-off between the smoothing penalty, the inventory, and the maintenance policy. Going further with a relatively high variance $(V=20)$, the obtained near-optimal integrated policy consists in producing at the maximum production rate for all periods. In this situation, smoothing is perfectly achieved (set-up cost, $S C$, is null).

\section{CONCLUSION}

In this paper we considered a manufacturing system made of a single machine that is subject to random failures. In order to reduce the failure frequency, a periodic preventive maintenance policy with minimal repair at failure is adopted. The production system must satisfy a random product demand over a finite planning horizon with a given required service level. The finite horizon is divided into equal periods. A mathematical model has been developed in order to derive a joint near-optimal production plan and preventive maintenance schedule minimizing the total cost of production, maintenance and inventory, taking into account constraints related to the production system capacity, the service level to be satisfied and the inventory balance.

Compared to previous works, a different cost modelling approach has been proposed. Furthermore, an integrated (not sequential) optimization of the production plan and the maintenance schedule has been proposed. It takes into account the influence of the production rate variation on the production system failure rate. Finally, expressing the set-up cost as being proportional to the production rate variation between successive periods, allowed reducing the penalty induced by excessive variation of the production rate over the planning horizon.

The proposed modelling approach has been illustrated through a numerical example. A sensitivity study with respect to the set-up cost has been performed in order to show the impact of the production plan smoothing on the obtained solution.

The trade-off between the smoothing penalty and the production plan, the inventory, and the preventive maintenance schedule has also been discussed. We finally studied the effect of the demand variability on the smoothing penalty, the production and maintenance plans, and on the total expected cost.

Extensions to this work are under consideration. One of them consists in the investigation of more realistic situations in which preventive maintenance actions are imperfect and have nonnegligible durations. Another extension of this work would consist in going beyond the limitation imposed by the linear relationship between the production rate and the failure rate of the system. More general expressions should be investigated empirically and analytically.

\section{REFERENCES}

[1] Barlow RE and Hunter LC (1960) “Optimum Preventive Maintenance Policies". Operations Research, vol. 8, pp 90-100.

[2] Wang H (2002) “A survey of maintenance policies of deteriorating systems”. European Journal of Operational Research, vol. 139(3), pp. 469-489.

[3] Brandolese M, Fransi M and Pozzeti A (1996) "Production and maintenance integrated planning". International Journal of Production Research, vol. 34(7), pp.2059-2075. 
[4] Chelbi A and Rezg N (2006) "Analysis of a production/inventory system with randomly failing production unit subjected to a minimum required availability level". International Journal of Production Economics, vol. 99, pp. 131-143.

[5] Pal B, Sana SS and Chaudhuri KS (2013) "A mathematical model on EPQ for stochastic demand in an imperfect production system". Journal of Manufacturing Systems, vol. 32, pp 260-270.

[6] Rezg N, Dellagi S and Chelbi A (2008) "Optimal strategy of inventory control and preventive maintenance”. International Journal of Production Research, vol. 46(19), pp. 5349-5365.

[7] Tambe PP and Kulkarni MS (2015) "A superimposition based approach for maintenance and quality planoptimization with production schedule, availability, repair time anddetection time constraints for a single machine". Journal of Manufacturing Systems, vol. 37, pp 17-32.

[8] Dellagi S, Rezg N and Xie X (2007) "Preventive maintenance of manufacturing systems under environmental constraints". International Journal of Production Research, vol. 45(5), pp.12331254.

[9] Dahane M, Clementz C and Rezg N (2010) "Effects of extension of subcontracting on a production system in a joint maintenance and production context". Computers \& Industrial Engineering, vol. 58(1), pp. 88-96.

[10] Nourelfath M, Fitouhi MC and Machani M (2010) "An integrated model for production and preventive maintenance planning in multi-state systems". IEEE Transactions on Reliability, vol. 59(3), pp. 496-506.

[11] Nourelfath M and Châtelet E (2012) "Integrating production, inventory and maintenance planning for a parallel system with dependent components". Reliability Engineering and System Safety, vol. 101, pp. 59-66.

[12] Mifdal L, Hajej Z and Dellagi S (2015) "Joint Optimization Approach of Maintenance and Production Planning for a Multiple-Product Manufacturing System". Mathematical Problems in Engineering, vol. 2015, Article ID 769723, 17 pages, 2015. doi:10.1155/2015/769723

[13] Hajej Z, Rezg N and Dellagi S (2011) "Optimal integrated maintenance/production policy for randomly failing systems with variable failure rate". International Journal of Production Research, vol. 49(19), pp. 5695-5712.

[14] Hajej Z, Dellagi S and Rezg N (2011) "Production/Maintenance Policies Optimization with Operational Age Concept in a Subcontracting Constraint".18th IFAC World Congress, vol. 18(1), pp. 5213-5218, Milan, Italy.

[15] Hajej Z, Dellagi S and Rezg N (2014) "Joint optimization of maintenance and production policies with subcontracting and product returns". Journal of Intelligent Manufacturing, vol. 25(3), pp. 589-602.

[16] Ayed S, Dellagi S and Rezg N (2012) "Joint optimisation of maintenance and production policies considering random demand and variable production rate". International Journal of Production Research, vol. 50(23), pp. 6870-6885.

[17] Holt CC, Modigliani F, Muth JF and Simon HA (1960) "Planning Production, Inventory and Work Force". Prentice Hall, Englewood Cliffs, NJ.

[18] Cox D (1972) "Regression models and life-tables". Journal of the royal statistical society, vol. 34(2), pp187-220. 